\title{
Os afixos da beleza e da feiura - uma leitura de Umberto Eco
}

\section{The affixes of beauty and ugliness - an approach to Umberto Eco's books}

\author{
Jéssica Camara Siqueira*
}

\begin{abstract}
Resumo: A formação de palavras na língua portuguesa ocorre principalmente por meio do processo de derivação. Considerando a importância dos afixos para a criação de novas palavras na língua, analisaram-se prefixos e sufixos formantes de vocábulos de duas noções - beleza e "feiura", a partir da seleção de adjetivos derivacionais das obras $A$ história da beleza e $A$ história da feiura, ambas de Umberto Eco. A análise focou-se na observação das similitudes e distinções dos afixos. As principais similitudes encontradas foram: afixos que intensificam o sentido das bases, prefixos que denotam negação, e sufixos de formação nominal. Nas distinções, observaram-se prefixos com conotação de reiteração e extensão para a noção de beleza; associados à feiura, valores negativos ou ausência de um traço semântico relativo à base. Quanto aos sufixos, à beleza, destacaram-se valor de grandeza, similitude, semelhança e superioridade; à feiura, conotação pejorativa, diminutiva e associação à natureza animal. A análise dos afixos permitiu verificar que o processo derivacional não só é responsável pela produtividade como pela criatividade na formação de palavras.
\end{abstract}

Palavras-chave: Afixos; Beleza; Derivação; Feiura; Morfologia.

\begin{abstract}
The word formation in the Portuguese language occurs extensively through derivation processes. Considering the importance of affixes to the creation of new words, this paper aims at analyzing prefixes and suffixes which form concepts of two notions - beauty and ugliness, based on the selection of derivational adjectives of the works History of Beauty and On Ugliness, by Umberto Eco. This analysis is focused on the observation of similarities and differences involving affixes. The main similarities found were affixes which intensified the meaning of the root, prefixes which are usually related to negative meaning and suffixes with nominal formation. Regarding the differences, prefixes with repetitive and extensive connotation for beauty were observed. Negative values or lack of semantic characteristic related to the base for ugliness were also found. In relation to suffixes one may highlight that greatness, similitude, similarity and superiority values were detected. In relation to ugliness, depreciatory, diminutive and animal connotations and association with animal nature were equally found. The analysis of the affixes allows to conclude that the derivational process is not only responsible for productivity but also for creativity in word formation.
\end{abstract}

Keywords: Affixes; Beauty; Derivation; Ugliness; Morphology.

\section{Introdução}

A formação de palavras na língua portuguesa concentra-se principalmente no processo de derivação (PETTER, 2003). Sufixos e prefixos são responsáveis por grande parte das palavras formadas de modo vernacular na língua portuguesa. Considerando a importância dos afixos para a criação de novas palavras na língua, analisaremos os prefixos e sufixos formantes

\footnotetext{
* Doutoranda em Letras, Filologia e Língua Portuguesa na Universidade de São Paulo- USP. Bolsista Capes.
} 
de vocábulos de duas noções "beleza" e a "feiura".

A partir da leitura das obras A história da beleza (2007a) e A história da feiura (2007b) de Umberto Eco, foi observada a vasta ocorrência de adjetivos com formações derivacionais que permitiriam a análise pormenorizada de seus afixos. Nessa análise, observou-se a ocorrência de alguns afixos específicos para cada noção, mas também alguns afixos comuns às noções da beleza e da feiura.

As noções de beleza e feiura são apresentadas pelo autor a partir de excertos de trechos literários, que, segundo Eco, representam as duas noções. A partir desses excertos, extraímos todos os adjetivos com formação derivacional e os analisamos, verificando a frequência de aparição, o tipo de afixo, e seu sentido para compor o vocábulo.

O objetivo da análise, portanto, é verificar quais são os afixos mais representativos das noções de beleza e feiura, tanto os de caráter exclusivo para cada noção como aqueles com sentido comum a ambas.

\section{Pressupostos teóricos}

No intuito de resgatar noções básicas que fundamentam os estudos léxicos, retomaremos alguns conceitos tratados por Biderman (2001) em sua obra Teoria linguística: teoria lexical e linguística computacional. A propósito da unidade léxica, a autora resgata diferentes perspectivas, basicamente concentrando as discussões acerca das noções de "morfema", "lexema", "lexia" e "palavra".

Em relação à imprecisão quanto ao uso do termo "palavra", principalmente no âmbito dos estudos lexicais, cunhou-se outro termo para designar a unidade léxica abstrata de uma língua, o lexema. Assim, o lexema corresponde àquilo que uma língua oferece de possibilidades para seu uso. No entanto, quando o lexema é colocado no discurso, utiliza-se outra denominação, lexia. A lexia, segundo o "grau de soldadura" entre os demais elementos, pode ser considerada simples ou complexa, indicando assim tanto as vias de fluxo e refluxo do sistema, como seu índice de coesão interna (BIDERMAN, 2001).

A noção de palavra, mesmo sendo a unidade léxica mais popular, é também a que traz em seu bojo mais polêmicas quanto à sua constituição. Dentre os vários critérios para delimitação de uma palavra, Biderman (2001) aponta três: o critério fonológico, o gramatical ou morfossintático e o semântico. Contudo, mesmo com tais critérios, às vezes é difícil delimitar o escopo de uma palavra, principalmente porque ela também pode se subdividir em 
unidades menores de significado, a exemplo do morfema.

O morfema é a unidade mínima portadora de significado num enunciado. Diferente do fonema, também considerado como unidade mínima, só que da segunda articulação, o morfema é o menor elemento que possui um significado individualizado, antes de passar para o nível fonológico (BIDERMAN, 2001).

Sobre a noção e as principais tipologias do morfema, Mattoso Câmara assim os define:

[...] como forma linguística o morfema tem significante (o material fônico) e um significado, que e a noção gramatical que ele traz para o semantema. Do ponto de vista do significante, o morfema pode ser: 1) Aditivo: um segmento fônico (um fonema ou grupo de fonemas); 2) Subtrativo: a supressão de uma parte do semantema; 3) Alternativo: a substituição de fonemas do semantema que passa a ter duas ou mais formas alternantes; 4) Reduplicativo: a repetiçãoreduplicação (...); 5) de Posição: a posição do semantema em relação a outro na enunciação; 6) Zero: a ausência de qualquer morfema aditivo (...) criandose uma oposição (...) (CÂMARA JÚNIOR, 2000, p.170).

Depois de apresentadas as principais noções que encabeçam os estudos morfológicos, podemos falar da Morfologia. A Morfologia, no âmbito linguístico, corresponde ao estudo da forma da palavra. No entanto, para tal estudo é preciso definir sua unidade mínima. Para isso, pode-se considerar tanto a palavra, se o objetivo for verificar as relações entre sentenças ou sintagmas, como o morfema, se a opção for uma abordagem de caráter estruturalista. No âmbito deste trabalho será utilizado o morfema como unidade mínima, já que o intuito é a segmentação e a análise dos processos de associação dos morfemas (PETTER, 2003).

Os estudos morfológicos se encaminham basicamente para dois campos: a morfologia lexical, dedicada aos mecanismos de formação de novas palavras; e a morfologia flexional voltada aos mecanismos que acrescentam informações gramaticais às palavras. A morfologia lexical ocorre basicamente a partir de dois processos, a derivação e a composição, sendo o primeiro mais recorrente. Já a morfologia flexional está mais relacionada às relações gramaticais, a exemplo das flexões de gênero e número (nomes) e modo e pessoa (verbo) (SANDALO, 2001).

Para análise será utilizada a abordagem da morfologia lexical, mais especificadamente o processo de derivação. A derivação lexical é o processo de formação de palavras mais produtivo e criativo da língua portuguesa. Basicamente é formado a partir de uma base (radical/raiz) e o acréscimo de um afixo (prefixo e/ou sufixo). A raiz corresponde ao elemento considerado irredutível e comum a um grupo de palavras derivadas, a exemplo de mar- (marinha; mar-inheiro; mar-ítimo, etc.). O radical, por sua vez inclui a raiz e também alguns 
elementos afixais que funcionam como um "suporte" para a formação de outros afixos (ex.: marinh- "a"" e "eiro"). Os afixos apresentam funções sintático-semânticas bem definidas, tendo assim o papel de serem combinados à base e conferir-lhe um valor semântico (PETTER, 2003).

O que diferencia basicamente os prefixos e sufixos, é que o primeiro se agrega no início da unidade lexical, enquanto o outro na parte final. Contudo, há casos em que tanto prefixo como sufixo podem se unir a uma unidade léxica, fato que pode ser estudado separadamente, já que a ordem de ocorrência desses acréscimos pode ser relevante para se compreender a natureza dessas derivações. Tal fenômeno é distinto do conhecido como "parassíntese", quando simultaneamente prefixo e sufixo se agregam a uma unidade lexical, sendo improvável a formação de elementos intermediários com apenas um dos afixos (MARONEZE, 2012).

Como o objetivo da análise é verificar a estrutura morfológica das palavras que fazem parte do campo lexical da beleza e da feiura, segundo Eco (2007a; 2007b), nos limitaremos à categoria nominal, mais especificadamente os adjetivos. Considerando o substantivo como elemento central da construção morfossintática, junto ao verbo, o adjetivo teria como papel especificá-lo, indicando sua dependência em relação ao primeiro por meio da concordância (gênero, número, grau) (CÂMARA JÚNIOR, 1975). Assim, a partir dos substantivos "beleza" e "feiura", são analisados os adjetivos que se reportam a essas noções, compondo seus campos lexicais.

No âmbito da Estilística, poderíamos inferir que tais substantivos funcionam como termos identificadores, ou seja, aqueles que reúnem a ideia comum aos demais termos de uma determinada serie sinonímica (LAPA, 1998). Nesse caso, são escolhidos não apenas por seu caráter substantivo, mas por serem os termos mais gerais e abstratos, aspectos comumente utilizados para tal delimitação.

\section{As noçóes de beleza e feiura}

Em suas obras sobre a história da beleza e da feiura, Eco (2007a; 2007b) procura resgatar como essas noções foram entendidas no decorrer do tempo, trazendo, para ratificar sua perspectiva de belo e feio, obras de arte e textos literários de diferentes épocas.

Depois de observar as mudanças de concepção de beleza e feiura no decorrer do tempo, "traduzidas" pela arte, o autor constata que de modo geral o cerne para a compreensão dessas noções está ligado a uma determinada época e cultura, tendo, portanto, um caráter relativo.

Todavia, mesmo com tal relatividade para se encarar esses conceitos, o autor afirma, 
em diferentes momentos das obras, que no decorrer da história buscou-se um modelo de estabilidade para a compreensão do belo e do feio, principalmente no mundo ocidental (ECO, 2007b).

Uma primeira constatação entre as duas noções é sua relação de oposição. Enquanto a noção de beleza está associada a um prazer estético pelo gosto, a noção de feio seria o oposto disso, ou seja, o desprazer, a repulsa, o incômodo. Assim, verificamos que as duas noções estão intimamente ligadas à estética, a ciência que tem como objeto o juízo da apreciação aplicado na distinção entre o belo e feio (LALANDE, 1999).

Esse prazer estético relacionado ao belo traz em seu bojo o prazer da fruição, associado à harmonia, equilíbrio, mas principalmente determinado por aquilo que um grupo social, culturalmente, identifica como belo (COSTA, 2004). Uma máscara ritual africana, por exemplo, para os padrões estéticos ocidentais é considerada repulsiva e desarmônica. Contudo, para a cultura africana é bela, pois está representando uma divindade benévola.

O belo e o feio também aparecem, em grande parte das obras, associados ao caráter apolíneo e dionisíaco, estudados por Nietzsche em o Nascimento da tragédia (NIETZSCHE, 1999). Nessa obra, o autor reinterpreta os antigos valores clássicos, questionando os valores morais e religiosos do final de século XIX, além de confrontar tal comportamento com as mudanças científicas e culturais ocorridas no início do século XX. Para representar a dinâmica dessas transformações, o autor resgata as figuras de Apolo e Dionísio, e aquilo que cada uma representa no contexto da cultura ocidental. O apolíneo, relativo ao belo, seria tudo aquilo que agrada associado por sua vez à harmonia, simetria, proporção, ordem, moderação e equilíbrio. Já o caráter dionisíaco, em oposição, associa-se ao feio, tem a conotação daquilo que perturba que causa desordem, incômodo e caos, motivado pelo instinto e vontade (SEINCMAN, 2008).

De forma geral, essa dicotomia, apolíneo e dionisíaco, esteve presente em grande parte da história da arte ocidental, tendo uma mudança mais considerável no século XX, com a introdução dos valores modernistas, que relativizaram a perspectiva de se olhar o belo e o feio, e com o desenvolvimento da indústria cultural de massa, que associou a beleza ao lazer e ao entretenimento (COSTA, 2004).

No âmbito deste artigo, trataremos o conceito de beleza e feiura como valores estéticos associados ao gosto, refletidos e refratados nas artes plásticas e na literatura clássicas, selecionadas por Umberto Eco para a composição de suas obras sobre a História da Beleza e da Feiura.

(C) Jéssica Camara Siqueira, p. 40-54 


\section{Descrição metodológica}

A partir da leitura das obras História da beleza e História da feiura, de Umberto Eco, foram extraídos, manualmente, de todos os excertos literários, os adjetivos de formação derivacional. Como o original está em italiano, foi considerada para a análise a tradução realizada por Eliana Aguiar. Contudo, é importante ressaltar que pelo fato de ser uma tradução, acaba-se por incorporar também outra perspectiva de leitura, além daquela do autor original. Dessa forma, observando, por exemplo, a versão traduzida no português de Portugal, pode-se verificar algumas mudanças nas escolhas dos termos e expressões. Assim, podemos constatar que a seleção do corpus foi feita com base nas noções de beleza e feiura segundo a leitura de Eco e Aguiar.

A lista de adjetivos em seguida foi separada em duas, uma para cada noção, contendo os seguintes campos para análise: termo, prefixo, sufixo, sentido; observações. Além desses campos, foi considerada a frequência dos sufixos, que foram numerados em ordem de ocorrência. Como o objetivo foi analisar as formas derivacionais, não foram considerados para a análise os adjetivos com outros tipos de formação.

A partir das indicações do tipo prefixal e sufixal incorporado em cada unidade lexical, foi feita a análise, observando os afixos similares e distintivos para cada noção.

\section{Análise dos afixos da beleza}

Como objetivo desta análise estava centrado nos adjetivos com formações derivacionais, excluíram-se outros tipos de formações adjetivais, como a composição, bem recorrente no corpus elegido. Considerando o tipo de ocorrência e não sua frequência repetida dentro da obra, chegou-se a um número de 183 vocábulos analisados.

Desses 183 vocábulos, todos eram formados por sufixos, e apenas 19 possuíam prefixos, o que determina a predominância do uso desse afixo na formação de palavras relacionadas à beleza.

Os prefixos encontrados foram de cinco tipos (CUNHA, 1982):

- a-: Ocorre com função prefixal na formação de alguns verbos e de seus particípios, sem alterar o significado do vocábulo. Ex.: a-calmada; agraciada; a- longado.

- em-/en-: Indica posição interior, voltado para dentro. Ex.: en-feitado; en- 
riquecido; em-belezado.

- re- : Indica volta, retorno, repetição. Ex.: re-finado; re-ordenado.

- trans-: Indica noção de "além de" e "através de". Ex.: trans-cedental; transparente; trans-lúcido.

- des-: Ação contrária ao que e expressa no termo primitivo. Ex.: des-temido.

Dentre os prefixos analisados, é interessante destacar o último apresentado acima, des. Esse prefixo aparece apenas no exemplo dado e com isso, indiretamente, ratifica uma escolha por vocábulos que conotem aspectos diretamente positivos, para conotar a noção de beleza. Assim, opta-se por afirmar o caráter da beleza com afixos que intensifiquem determinados aspectos da base e não utilizar uma base com conotação negativa para ser contrastada com o uso de um afixo, como é o caso de des-temido.

Outro aspecto a ser destacado sobre os prefixos analisados é a utilização do prefixo trans-. Diferente dos demais que também aparecem na análise dos vocábulos relativos à feiura, o prefixo trans- aparece apenas no contexto da beleza. Nesse caso, uma hipótese para tal escolha de uso estaria vinculada ao seu sentido, "ir além de alguma coisa", conotação geralmente associada com algo positivo, nesse contexto.

Os sufixos apresentam-se em maior número e com uma diversidade maior. Os sufixos mais recorrentes foram:

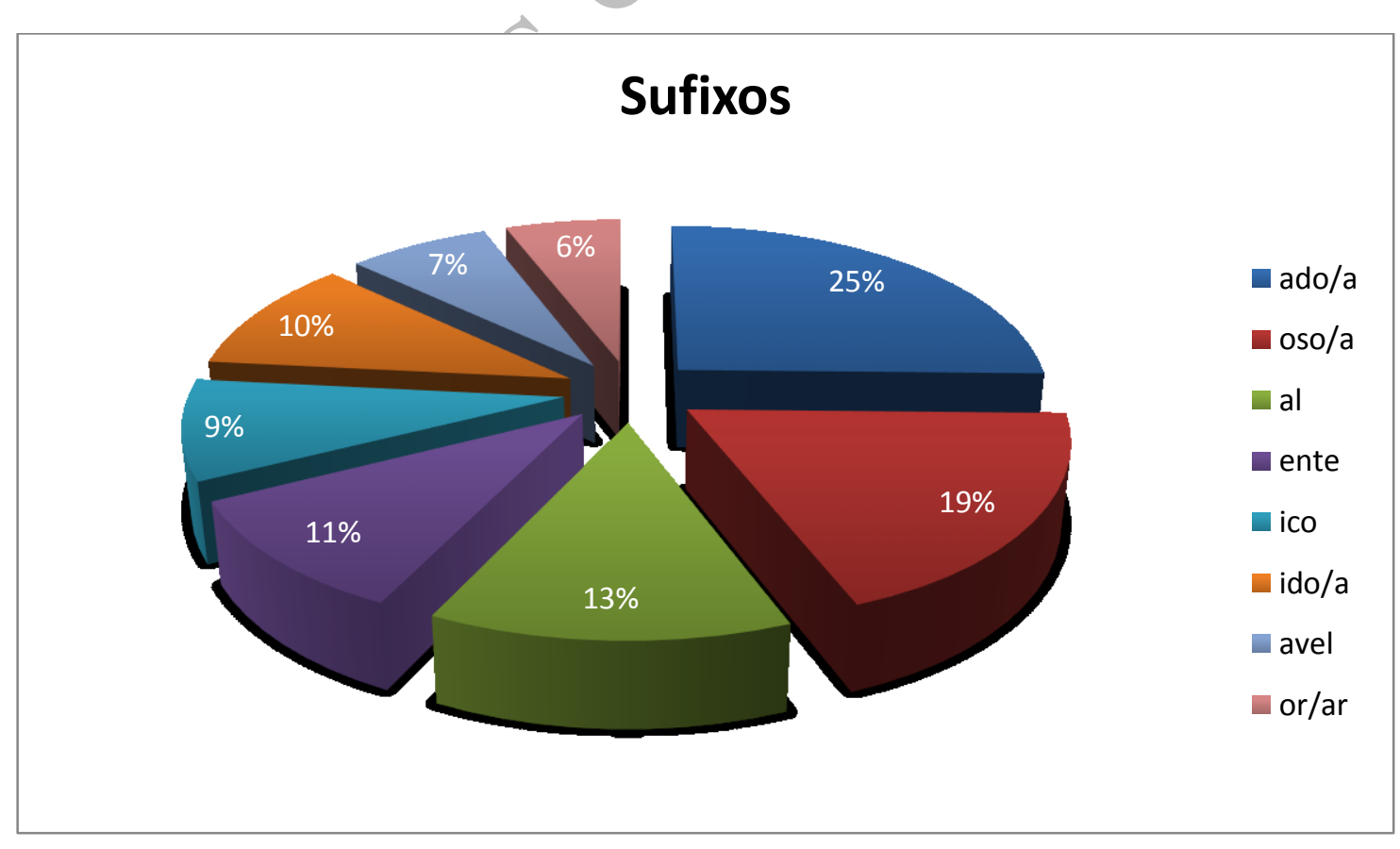

Gráfico 1- Sufixos da beleza

Fonte: Elaboração própria 
Uma primeira constatação ao olharmos o gráfico é perceber a variedade de sufixos, com destaque para uma concentração das formações derivacionais provenientes de nominalizações. Nesse caso, temos como exemplos:

- -ado/a : cor-ado; delic-ada; frutific-ada; embelez-ada.

- -ico: estét-ico; hero-ico, fantást-ico.

- -ido/a: cál-ido; când-ido; enlev-ado; esculp-ido.

Além das nominalizações, há os sufixos que possuem determinado sentido que é acrescido à base, ampliando seu significado. Como exemplo dessas formações temos:

- -oso/a: Noção de "provido de". Ex.: form-oso; esplendor-oso, maravilh-oso; frond-osa.

- -ente: Indica qualidade e estado. Ex.: sorrid-ente, resplandesc-ente;

- -al: Relação de pertinência. Ex.: essenci-al; angelic-al; divin-al; form-al.

- -ar/or: Adjetivos formados a partir de substantivos com sentido de relação e pertinência. Ex.: encantad-or; sol-ar; sedut-or; lun-ar.

- -ável: Forma adjetivos com temas verbais ora com valor ativo, ora passivo. Ex.: agrad-ável; memor-ável; est-ável.

Além desses sufixos, foram observados outros em menor ocorrência e também com conotações que se somavam ao sentido da base. Assim, temos:

- -eo: Ocorre na formação de adjetivos oriundos de substantivos, tendo a noção de relação e semelhança. Ex.: apolín-eo; rosác-eo; violác-eo; curvilíneo.

- -il: Relação de semelhança. Ex: febr-il; puer-il; primaver-il.

- -ivo: Forma adjetivos oriundos de verbos com noção de modo de ser e ação. Ex.: express-ivo; compreens-ivo; alt-ivo.

- -az: Forma adjetivos com noção de grandeza. Ex.: loqu-az; ten-az; perpicaz; viv-az.

- -eiro: Indica certa tendência de caráter. Ex.: trigu-eiro; verdade-eiro.

- -́́ssimo: Superlativo de superioridade. Ex.: bel-íssimo; braqu-íssimo; fortíssimo.

Podemos constatar que, além dos sufixos que indicam nominalizações ou são utilizados para formações de adjetivos a partir de verbos, há alguns que são usados especificadamente no contexto da noção de beleza. O exemplo mais óbvio é o sufixo -az, que indica ideia de grandeza. Outras ocorrências que ratificam tal afirmação podem ser vistas em -eo e ar/or, que indicam pertinência e semelhança, e em -ivo, que representa “um modo de ser". Pode-se, ainda, destacar -íssimo, superlativo de superioridade, geralmente atrelado a uma conotação positiva. Esse superlativo, no entanto, também aparece no contexto da feiura, só que em menor número. 


\section{Análise dos afixos da feiura}

Uma primeira observação acerca dos afixos da feiura é constatar que são em maior número que aqueles que remetem à beleza. Uma possível explicação, talvez, seja pelo fato de que há um maior número de nomes (substantivos e adjetivos) no corpus elegido, com outro tipo de formação estrutural, a exemplo da composição. Enquanto foram encontrados 183 yocábulos com formação derivacional para beleza, para a feiura foram coletados 273 vocábulos. Essa diferença expressiva se reflete em uma maior diversidade e número de ocorrência de afixos.

Assim como nos afixos da beleza, os sufixos também se destacam, tanto pelo caráter quantitativo como qualitativo. Contudo, ao contrário do que foi apresentado nos vocábulos que remetem à beleza, na feiura ocorre uma participação mais expressiva dos prefixos.

Foram encontrados onze tipos de prefixos, sendo que houve maior ocorrência de quatro: des-, in-/im-, en-, e a-. Abaixo um gráfico representativo da ocorrência dos prefixos nos excertos analisados:

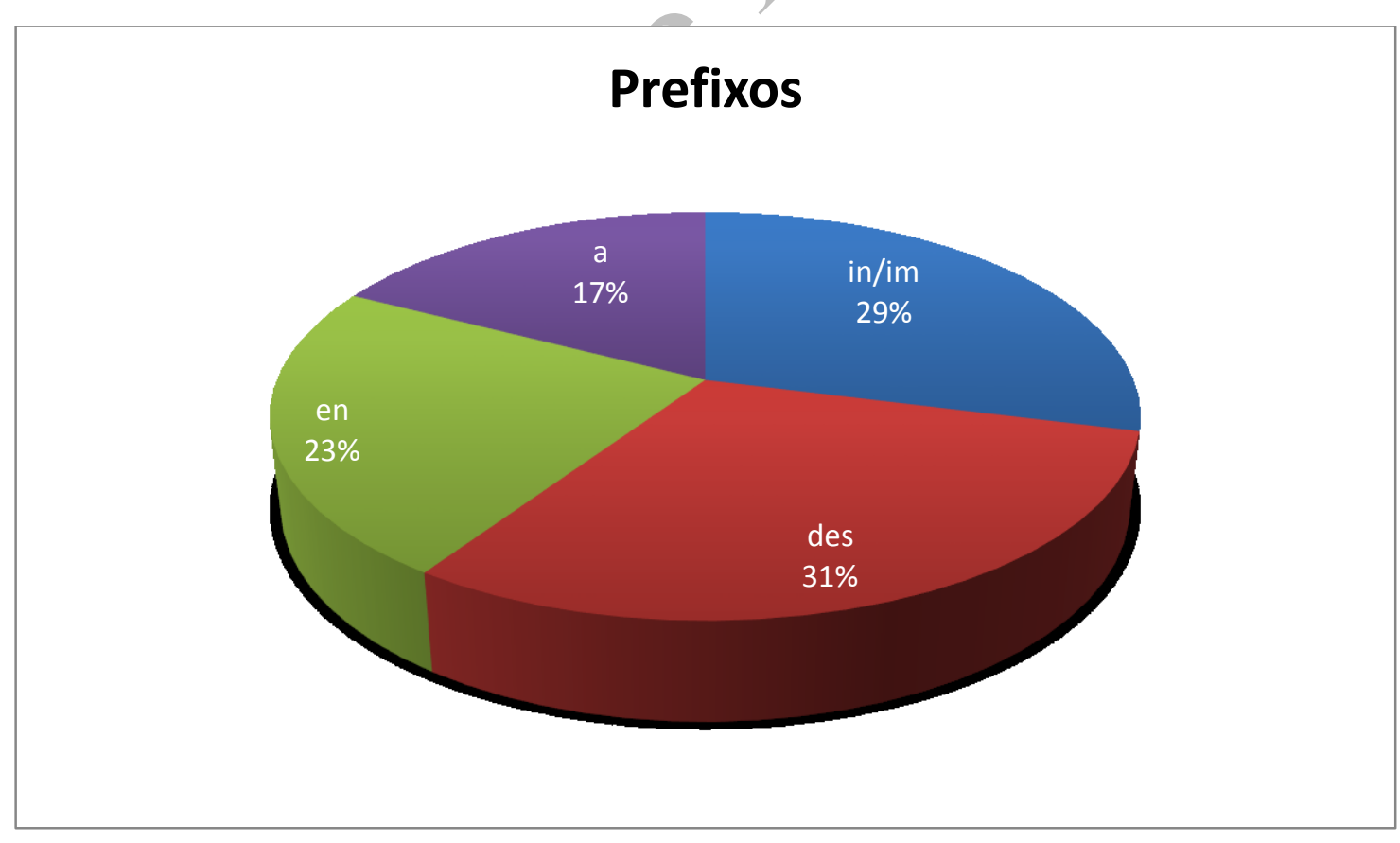

Gráfico 2- Prefixos da feiura

Fonte: Elaboração própria

Os prefixos mais recorrentes in-/im- e des- denotam um caráter de negação, ausência e oposição, que neste contexto atuam com a função de negar um valor ou um traço semântico 
geralmente relacionado ao oposto da feiura, a beleza. Assim temos:

- Des-: des-membrado; des-proporcional; des-carnado; des-figurado; desharmonioso; des-dentado; des-engonçado, etc.

- Im/In-: im-perfeito; im-puro; im-potente; in-completo; in-forme; in-sípido, etc.

Outro prefixo com função de negação semelhante é o a-, com frequência também considerável. Como exemplo, temos: a-pático; a-morfo; anormal; a-podrecido; a-trofiado; atormentado.

Com a conotação um pouco distinta, e mais recorrente, há o prefixo en-, que remete a intensificação ou desenvolvimento de algo. Diferente dos prefixos anteriores, que se agregam a uma base com conotação relativa à beleza, o prefixo en- geralmente se agrega a uma base que já traz em seu conteúdo uma conotação próxima ao sema da feiura. Como-exemplo desse uso temos: en-crespado; en-velhecido; en-grossado; en-ferrujado; en-sebado.

Os outros prefixos encontrados, em menor ocorrência são; dis-, es-, irr-, obs, sub-, tri, poli-, di-. As conotações desses prefixos basicamente tratam de dois aspectos: negação ou ausência de um traço semântico relativo à base, ou intensificação desse traço. Uma exceção são os prefixos com conotações quantitativas, como em tri-forme e poli-dáctilo, que nesse contexto possuem um caráter pejorativo.

Quanto aos sufixos, observa-se a ocorrência de um número superior ao de prefixos, ou seja, foram encontrados 85 prefixos para 252 sufixos. Com isso observamos, que assim como na noção de beleza, ocorrem mais formações derivacionais sufixais.

Dentre os sufixos mais recorrentes destacam-se os seguintes: -ado/a; -ido/a; -oso/a; udo/a; -ento; -al; -ente. As ocorrências podem ser visualizadas no gráfico abaixo: 


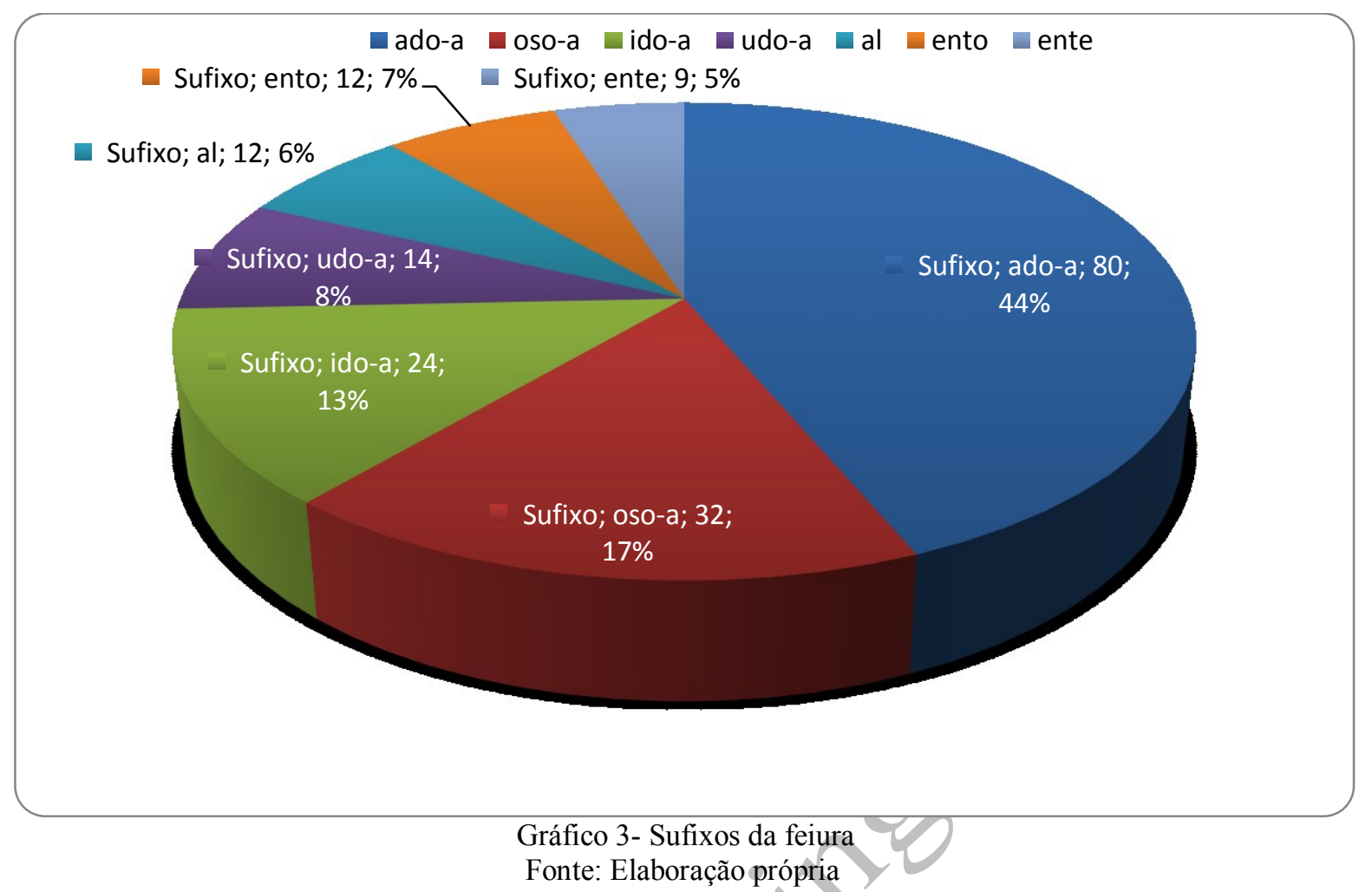

Dentre os sufixos de maior ocorrência, obseryamos que prevalecem aqueles que atuam na formação de nomes a partir de verbos, fenômeno também conhecido como nominalização. Assim, esses sufixos têm o sentido de "ação", "resultado de uma ação", ou mesmo referência ao "agente da ação". Podemos observar tais conotações nos exemplos abaixo:

- -ado/a: apag-ado; atrofi-ado; arrepi-ado; chup-ada; definh-ada; desajeitado; depen-ado.

- -ido/a: carcom-ida; envelhec-ida; ca-ído; desprov-ido; embrutec-ido.

- -udo/a; peit-uda; pelanca-uda; chifr-udo; linguar-udo; carranc-udo.

- -ento/a: noj-ento; fedor-ento; melequ-ento; lamac-ento; pardac-ento; vermelh-ento.

- -ente: repel-ente; estrid-ente; decad-ente; incongru-ente.

Nos casos de -ado/a e -ido/a, percebemos claramente as terminações do particípio dos verbos que se adjetivaram. No caso de -udo/a e -ento, há uma denotação de algo que "é provido de" ou "cheio de". Contudo, em ambos os casos, verifica-se uma conotação negativa.

De forma geral, observamos que grande parte desses sufixos, com a função de nominalização, também aparecem no contexto da beleza. Porém, os sufixos -ento/a e principalmente -udo/a, são mais característicos da noção de feiura, já que trazem arraigados em seu sentido uma conotação pejorativa e negativa.

Outro sufixo com grande ocorrência é -oso, observado na formação de adjetivos a partir 
de substantivos, estando presente tanto nas formações relativas à beleza como da feiura. Assim temos, por exemplo:

- Gordura (substantivo) - gordura-oso (adjetivo);

- Pavor (substantivo- pavor-oso (adjetivo);

- Verme (substantivo) - vermin-oso (adjetivo);

Quanto ao sufixo -al, com destacada ocorrência, observa-se a conotação de "relação" e "pertinência" atrelados ao seu sentido, podendo também aparecer na noção de beleza. No caso da feiura, temos os seguintes exemplos: infern-al; fec-al; besti-al; cemiteri-al.

Além desses sufixos mais recorrentes, foram observados outros. Abaixo os demais sufixos encontrados, seus respectivos significados e exemplos:

- -ável: Forma adjetivos com temas verbais ora com valor ativo, ora passivo. Ex.: detest-ável; abomin-ável.

- -ante: Noção de qualidade e estado. Ex.: ignor-ante; rutil-ante; repugn-ante.

- -ico/a: Participação, referência, relação. Ex.: cadáver-ico; colér-ico; diabólico; dionisí-aco.

- -il: Noção de referência e semelhança. Ex.: febr-il, doent-il; sen-il; host-il.

- -uça: Noção de grandeza, mas com conotação pejorativa. Ex.: dent-uça.

- -inha: Indica diminutivo. Ex.: Dan-inha; baix-inha; fe-inha.

- -ão: Valor aumentativo, com conotação pejorativa. Ex.: glut-ão; porcalh-ão;

- -onho: Indica estados expressivos. Ex.: Med-onho.

- -ino/a: Indica relação e/natureza de algo, acrescida nesse contexto uma conotação pejorativa. Ex.: capr-ino; bov-ino, can-ino.

Para finalizar, podemos verificar que alguns dos sufixos mencionados acima também aparecem na análise feita com os vocábulos que remetem à beleza. Todavia, há alguns sufixos que aparecem exclusivamente no contexto da feiura, principalmente por conta de seu traço pejorativo, a exemplo de: -ino/a e -ão, e os já citados -udo/a e ento.

\section{Conclusões}

Podemos observar, a partir da análise dos afixos, a importância desse processo de formação para constituição de palavras na língua. A escolha por duas noções opostas, mas estritamente vinculadas, comprova como o processo derivacional não só é responsável pela produtividade como pela criação de palavras novas.

Os prefixos, por exemplo, mesmo em menor número, apresentaram relevantes ocorrências. Comum às duas noções, observamos os prefixos que indicam negação ou oposição, a- e des-, e os que intensificam a noção expressa na base, a exemplo de -en/em. A noção de 
beleza apresenta particularmente dois tipos de prefixos o trans-, que indica "ir além de alguma coisa", e o re-, que está ligado ao sentido de repetição e retorno.

Já os prefixos que aparecem para conotar os adjetivos da feiura, além dos que são comuns à beleza, geralmente são usados para evidenciar um caráter da base, ora negando-o, como no caso de ir-regular, ou dando-lhe uma conotação negativa, como em sub-terrâneo. Há ainda alguns prefixos com conotações de quantidade, que nesse contexto adquirem um sentido negativo por representarem aberrações ou associações com animais, a exemplo de poli-dáctilo e tri-forme.

Os sufixos se encontram em maior número em ambas as noções, sendo que no caso da beleza aparecem em todos os vocábulos coletados. É comum também a ocorrência, em ambas as noções, de sufixos usados na nominalização, ou seja, formantes de adjetivos a partir de verbos ou de substantivos, a exemplo dos sufixos: -ado/a; -ido/a; -ico;-oso/a; -ável. Além de serem comuns às duas noções, também são os mais recorrentes em frequência. Contudo, há sufixos com outros sentidos, que também aparecem tanto para a noção de beleza quanto de feiura. Assim temos, -al referente à pertinência; -ente para indicar qualidade e -il que relativo à semelhança.

Confirmando o caráter distintivo das noções, há sufixos que demarcam traços sêmicos associados à beleza e a feiura. No caso da beleza, por exemplo, observamos a ocorrência de sufixos com as seguintes conotações: -az (sentido de grandeza); -eo (indica similaridade); ar/or (sentido de pertinência); -ivo (modo de ser); -eiro ( indica traço ou caráter de algo); e íssimo (superlativo de superioridade). Sobre este último, podemos destacar que mesmo aparecendo também na noção de feiura, é muito mais recorrente na noção de beleza, o que pode ser explicado pelo fato de seu valor estar mais associado a um caráter positivo, associado à beleza.

Os sufixos mais recorrentes da feiura também são marcantes e revelam uma carga negativa e pejorativa que têm o papel tanto de acentuar como de realmente identificar um adjetivo com o caráter negativo. Assim, sufixos como -uça (Ex.:dent-uça) e -udo/a (Ex.: peluda), ao se agregarem à base trazem em seu bojo uma conotação negativa ou pejorativa. Outros sufixos que também afetam o sentido da base com traços pejorativos são: -ento (ex.: melequento); -ão (Ex.: porcalh-ão); -onho (Ex.: med-onho). Há ainda aqueles sufixos que naturalmente não indicariam algo pejorativo, mas que no contexto da feiura ganham um sentido negativo. Podemos destacar como exemplos o -ina/o e -inho/a. No primeiro caso, o sufixo indica a 
natureza de algo, geralmente associada à natureza animal que é aproximada, pejorativamente da natureza humana, a exemplo de: capr-ina, equ-ina e bov-ina.Já no segundo caso, o sufixo inho/a geralmente é usado para o diminutivo, que nem sempre vem associado a algo negativo, mas que aparece em várias ocorrências dos excertos analisados como um traço sêmico pejorativo, a exemplo de baix-inho; gord-inho e fe-inho.

\section{Referências}

BIDERMAN, M.T. Teoria linguística: teoria lexical e linguística computacional. São Paulo: Martins Fontes, 2001. 272p.

CÂMARA JÚNIOR, J. M. Dicionário de Linguística e Gramática: referente à língua portuguesa. 21 a ed. Petrópolis: Vozes, 2000. 262p.

CÂMARA JÚNIOR. J.M. História e estrutura da Língua Portuguesa. Rio de Janeiro: Padrão, 1975. 258p.

COSTA, C. Questões de arte - o belo, a percepção e o fazer artístico. São Paulo: Moderna, 2004. 203p.

CUNHA, A.G. Dicionário etimológico Nova Fronteira da Língua portuguesa. 15 ed. Rio de Janeiro: Nova Fronteira, 1982. 840p.

ECO, U. (org.) História da beleza. São Paulo; Rio de Janeiro: Record, 2007a. 386p.

ECO, U. (org.) História da feiura. São Paulo; Rio de Janeiro: Record, 2007b. 394p.

LALANDE, A. Vocabulário técnico e critico de Filosofia. São Paulo: Martins Fontes, 1999. 420p.

LAPA, M.R. Estilística da língua portuguesa. São Paulo: Martins Fontes, 1998. 275p.

MARONEZE, B. Ordem de adição de afixos no português brasileiro: dados de unidades lexicais neológicas. Alpha, São Paulo, v.56, n.1, p.201-215, 2012.

NIETZSCHE, F. O nascimento da tragédia - ou o helenismo e o pessimismo. São Paulo: Companhia das Letras, 1999.184p.

PETTER, M.T. Morfologia. In: FIORIN, J.L. Introdução à Linguística. II Princípios de análise. São Paulo: Contexto, 2003. p.59-80. 
SANDALO, M.F.S. Morfologia. In: MUSSALIM, F.; BENTES, A. C. Introdução à Linguística - domínios e fronteiras. São Paulo: Cortez, 2001.p.181-206.

SEINCMAN, E. Estética da comunicação musical. São Paulo: Via littera, 2008.188p.

Artigo recebido em: 20.10 .2012

Artigo aprovado em: 21.02.2013 